\title{
Neuronal Glutamate Transporters Limit Activation of NMDA Receptors by Neurotransmitter Spillover on CA1 Pyramidal Cells
}

\author{
Jeffrey S. Diamond \\ Synaptic Physiology Unit, National Institute of Neurological Disorders and Stroke, National Institutes of Health, Bethesda, \\ Maryland 20892-4066
}

\begin{abstract}
Glutamate released at synapses in the CA1 region of the hippocampus escapes the synaptic cleft and activates extrasynaptic targets; it also may "spill over" into neighboring synapses and activate receptors there. Glutamate transporters in glial membranes restrict extrasynaptic diffusion, but it is unclear whether neuronal glutamate transporters also limit transmitter diffusion and receptor activation by spillover. I examined the effects of a low-affinity competitive NMDA receptor antagonist on EPSCs in acute hippocampal slices to distinguish receptors activated within active synapses from those activated by spill-
\end{abstract}

Communication at excitatory central synapses is mediated by the neurotransmitter glutamate, which, after the fusion of a synaptic vesicle with the presynaptic membrane, diffuses across a narrow synaptic cleft and activates postsynaptic receptors. At many central synapses, synaptically released glutamate acts at sites beyond the immediately apposed postsynaptic density. This phenomenon takes various forms but is commonly referred to as "spillover." At mossy fiber and calyceal synapses, glutamate can spill over between individual release sites and activate postsynaptic receptors in different active zones within the same synaptic structure (Trussell et al., 1993; Rossi et al., 1995; Silver et al., 1996; Scanziani et al., 1997; Overstreet et al., 1999). In other cases, glutamate spillover has been shown to activate extrasynaptic metabotropic glutamate receptors (Scanziani et al., 1997; Schrader and Tasker, 1997; Min et al., 1998; Vogt and Nicoll, 1999; Mitchell and Silver, 2000; Semyanov and Kullmann, 2000) and glial transporters (Bergles and Jahr, 1997; Bergles et al., 1997; Clark and Barbour, 1997).

In the present study, "spillover" refers to glutamate diffusion between single-site synapses, like that reported to occur between parallel fiber-stellate cell synapses in the cerebellum (Carter and Regehr, 2000) and between Schaffer collateral fiber-pyramidal cell synapses in the CA1 region of the hippocampus (Kullmann et al., 1996; Asztely et al., 1997; Lozovaya et al., 1999). Spillover in CA1 was examined here with D- $\alpha$-amino adipate (D-AA), a lowaffinity competitive NMDA receptor (NMDAR) antagonist whose efficacy depends on the synaptic concentration of gluta-

\footnotetext{
Received June 26, 2001; revised Aug. 9, 2001; accepted Aug. 10, 2001.

This work was supported by the National Institute of Neurological Disorders and Stroke Intramural Research Program. I thank Craig Jahr for valuable discussions and Chris McBain, Tom Otis, and Josh Singer for comments on this manuscript. I also thank Keiko Shimamoto (Suntory Institute for Bioorganic Research) for the generous gift of TBOA.

Correspondence should be addressed to Dr. Jeffrey S. Diamond, National Institutes of Health/National Institute of Neurological Disorders and Stroke, Synaptic Physiology Unit, Building 36, Room 2C09, 36 Convent Drive, Bethesda, MD 20892-4066. E-mail: diamondj@ninds.nih.gov.

Copyright (ㄷ) 2001 Society for Neuroscience $0270-6474 / 01 / 218328-11 \$ 15.00 / 0$
}

over. Glutamate spillover is observed between Schaffer collateral fiber synapses onto CA1 pyramidal cells only when transporters in the postsynaptic neuron are inhibited. Because glutamate transporters operate most effectively at negative membrane potentials, these results suggest that activation of NMDA receptors by spillover may depend on postsynaptic activity.

Key words: spillover; glutamate transporters; diffusion; Monte Carlo simulation; hippocampus; NMDA receptor mate (Clements et al., 1992). At room temperature and $34^{\circ} \mathrm{C}$, D-AA preferentially blocked slower components of the NMDAR EPSC in pyramidal cells, suggesting that the NMDARs underlying those components were activated by lower [Glu] than those contributing to the peak of the EPSC. Reducing extrasynaptic glutamate transport enhanced activation of those receptors encountering the lowest [Glu], suggesting that they were activated by transmitter that had traversed extrasynaptic territory. The effects of D-AA depended only weakly on the strength of electrical stimulation, suggesting that spillover may not require the coincident activation of multiple synapses.

In CA1, glutamate spillover is restricted by glial glutamate transporters (Asztely et al., 1997). Glial transporters mediate the large majority of glutamate uptake in this region (Rothstein et al., 1996; Tanaka et al., 1997; Bergles and Jahr, 1998; Lehre and Danbolt, 1998; Kojima et al., 1999; Diamond and Jahr, 2000). CA1 pyramidal cells also express glutamate transporters (Rothstein et al., 1994), but the physiological purpose of neuronal transporters in the hippocampus, including any role in limiting transmitter diffusion, remains unclear. In the present study, spillover was observed only when neuronal transporters were inhibited, either at room temperature or at $34^{\circ} \mathrm{C}$. These results indicate that neuronal glutamate transporters on CA1 hippocampal neurons help limit NMDAR activation by glutamate spillover. Because glutamate transport is most efficient at negative membrane potentials (Brew and Attwell, 1987; Barbour et al., 1991; Wadiche et al., 1995), the degree of spillover between synapses may depend on the activity of the postsynaptic cell.

\section{MATERIALS AND METHODS}

Slice preparation and solutions. Hippocampal slices $(400 \mu \mathrm{m})$ were prepared from 11- to 14-d-old Sprague Dawley rats, as described previously (Sakmann and Stuart, 1995) and in accordance with National Institute of Neurological Disorders and Stroke Animal Care and Use Committee guidelines. Slices were prepared and stored in artificial CSF (ACSF) containing (in mM):119 NaCl, $2.5 \mathrm{KCl}, 1.3 \mathrm{MgCl}_{2}, 2.5 \mathrm{CaCl}_{2}, 1$ $\mathrm{NaH}_{2} \mathrm{PO}_{4}, 26.2 \mathrm{NaHCO}_{3}$, and 11 glucose (bubbled with a 95\% $\mathrm{O}_{2}-5 \%$ $\mathrm{CO}_{2}$ mixture). After being cut in ice-cold ACSF on a vibratome (Leica, 


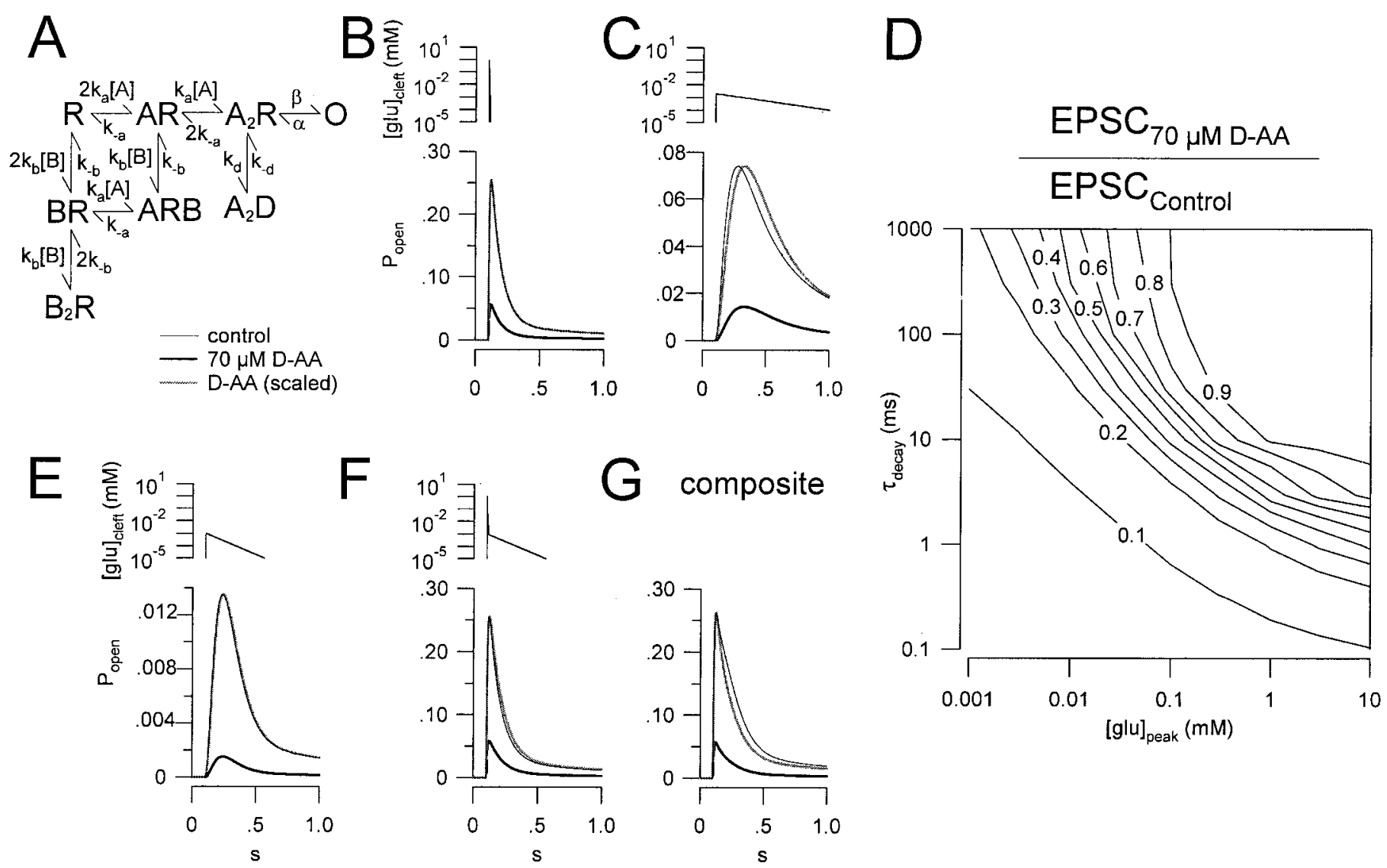

Figure 1. Simulating the effect of D-AA on NMDAR EPSCs. A, A kinetic model of the NMDAR (Clements et al., 1992; Lester and Jahr, 1992), incorporating the binding and unbinding of D-AA. Rates $\left(\mathrm{M}^{-1} \mathrm{sec}^{-1} \mathrm{or} \mathrm{sec}^{-1}\right): k_{\mathrm{a}}$ of $5 \times 10^{6} ; k_{-\mathrm{a}}$ of $5 ; k_{\mathrm{b}}$ of $7 \times 10^{6} ; k_{\mathrm{-b}}$ of $210 ; \alpha$ of $91.6 ; \beta$ of 46.5 ; $k_{\mathrm{d}}$ of 8.4; and $k_{-\mathrm{d}}$ of 1.8. $\mathrm{B}$, Model prediction of receptor response to an exponentially decaying glutamate concentration transient ([Glu] $]_{\text {peak }}$ of 1 mm; $\tau_{\text {decay }}$ of 1 msec; top panel) in "control" conditions (thin black line) and in $70 \mu \mathrm{M} \mathrm{D-AA} \mathrm{(thick} \mathrm{black} \mathrm{line).} \mathrm{The} \mathrm{D-AA} \mathrm{trace} \mathrm{is} \mathrm{also} \mathrm{scaled} \mathrm{(thick} \mathrm{gray} \mathrm{line)}$ to the same amplitude as control. $C$, As in $B$, except the glutamate transient is $2 \mu \mathrm{M}, 300$ msec. $D$, Contour plot of the blockade of D-AA of the simulated EPSC amplitude. [Glu $]_{\text {peak }}$ values were $0.001,0.003,0.01,0.03,0.1,0.3,1,3$, and $10 \mathrm{~mm} ; \tau_{\text {decay }}$ values were $0.1,0.3,1,3,10,30,100,300$, and $1000 \mathrm{msec}$. All combinations were simulated, resulting in a $9 \times 9$ array that was used to create the contour map in Igor Pro. $E$, As in $B$, except for [Glu] $]_{\text {peak }}$ of 1 $\mu \mathrm{M}$ and $\tau_{\text {decay }}$ of $100 \mathrm{msec} . F$, As in $B$, but with the glutamate transients from $B$ and $E$ combined to drive the simulation. $G$, As in $B$, except that the responses from $B$ and $E$ were added in a 1:6 ratio to simulate a multisynapse EPSC.

Nussloch, Germany), slices were stored at $34^{\circ} \mathrm{C}$ for $30 \mathrm{~min}$ and at room temperature for up to $7 \mathrm{hr}$ thereafter. In experiments requiring $\mathrm{Mg}^{2+}$ free conditions, slices were cut in normal ACSF but were stored in solution in which $\mathrm{MgCl}_{2}$ was replaced with $\mathrm{CaCl}_{2} ;$ kynurenic acid (1 mM) was added to the $\mathrm{Mg}^{2+}$-free storage solution to diminish excitotoxicity. ACSF, equilibrated with the $\mathrm{O}_{2}-\mathrm{CO}_{2}$ mixture, superfused the recording chamber at a rate of $2 \mathrm{ml} / \mathrm{min}$. Except where noted, experiments were performed at room temperature $\left(21-23^{\circ} \mathrm{C}\right)$. Extracellular solutions contained picrotoxin $(100 \mu \mathrm{M})$ and 6,7-dinitroquinoxaline-2,3-dione (DNQX) $(10 \mu \mathrm{M}$, except for the experiments described in Fig. $3 A)$ to block $\mathrm{GABA}_{\mathrm{A}}$ receptors $\left(\mathrm{GABA}_{\mathrm{A}} \mathrm{Rs}\right)$ and AMPA receptors (AMPARs), respectively. In recordings of synaptic transporter currents (see Figs. $3 B, 4), 5 \mu \mathrm{M}( \pm)$-3-(2-carboxypiperazin-4-yl)-propyl-1-phosphonic acid $[( \pm)-C P P]$ was also included to block NMDARs. The extracellular solution in excised patch experiments contained $130 \mathrm{~mm} \mathrm{NaCl}, 3.8 \mathrm{~mm}$ $\mathrm{CaCl}_{2}, 10 \mathrm{~mm}$ HEPES, and $10 \mu \mathrm{M}$ glycine and was adjusted to $\mathrm{pH} 7.4$ with $\mathrm{NaOH}$. Internal pipette solutions contained $120 \mathrm{~mm}$ $\mathrm{X}^{+}$methanesulfonate, $10 \mathrm{~mm}$ EGTA, $0.2 \mathrm{~mm} \mathrm{NaGTP,} 2 \mathrm{~mm} \mathrm{MgATP}$ and $20 \mathrm{~mm}$ HEPES, in which the cation $\mathrm{X}^{+}$was $\mathrm{NMDG}^{+}$for the experiments described in Figure $8 D, \mathrm{Cs}^{+}$for all other neuronal and excised patch recordings, and $\mathrm{K}^{+}$for astrocyte recordings. In the experiments performed at $34^{\circ} \mathrm{C}$ in the absence of external $\mathrm{Mg}^{2+}, \mathrm{QX}-314(5 \mathrm{~mm})$ was included in the patch pipette to reduce excitability of the postsynaptic cell. All internal and external solutions were adjusted with sucrose, if necessary, to 290-300 mOsm. Reagents were obtained from Sigma (St. Louis, MO), except for kynurenic acid and glutamate (Tocris Cookson, Ballwin, MO) and D,L-threo- $\beta$-benzyloxyaspartate (TBOA), which was a generous gift from Keiko Shimamoto (Suntory Institute for Bioorganic Research, Osaka, Japan).

Electrophysiology. Slices were visualized on an upright fixed-stage microscope (Zeiss, Thornwood, NY) equipped with infrared-differential interference contrast optics. Recordings were made with an Axopatch 1D amplifier (Axon Instruments, Foster City, CA), and data were acquired (sample frequency, 5-10 kHz; filter frequency, 2-5 kHz) and analyzed with software written in Igor Pro (WaveMetrics Inc., Lake Oswego, OR). Patch electrodes had tip resistances of 2-5 $\mathrm{M} \Omega$ [higher with $N$-methylD-glucamine (NMDG)-based internal solution]; access resistance was monitored throughout each experiment, was typically $<20 \mathrm{M} \Omega$ (measured by the peak of the charging current induced by a $1 \mathrm{mV}$ step), and was not compensated. EPSCs and synaptically activated transporter currents (STCs) were elicited with a blunted bipolar stimulating electrode (115 $\mu \mathrm{m}$ spacing) placed in stratum radiatum 100-200 $\mu \mathrm{m}$ from the soma of the recorded cell. In excised patch experiments, rapid application of glutamate was achieved with a multibarreled flow pipe attached to a piezoelectric bimorph (Piezo Systems, Cambridge, MA). Twenty to $80 \%$ solution exchange was typically $100 \mu \mathrm{sec}$ (see Fig. $3 \mathrm{C}$ ). Voltages have not been corrected for a $\sim 10 \mathrm{mV}$ junction potential. Moving the membrane potential from negative to positive potentials resulted in a temporary reduction in input resistance and EPSC amplitude, likely because of activation of voltage-dependent conductances. The input resistance and EPSC amplitude increased together and stabilized within several minutes (see Fig. 8). Unless otherwise indicated, all data are reported as mean $\pm \mathrm{SD}$, and $p$ values are from paired $t$ tests.

Simulations. NMDAR-D-AA kinetic simulations (Fig. 1) were per- 
formed using the Simulation Control Program (Simulation Resources Inc., Redlands, CA); diff usion simulations (see Fig. 9) were performed using MCell (Stiles et al., 1996), Monte Carlo simulation software designed specifically to model chemical synaptic transmission. In both cases, NMDARs were represented by a Markov model (Clements et al., 1992; Lester and Jahr, 1992); neuronal transporters were configured by modifying existing transporter models (Wadiche and Kavanaugh, 1998; Otis and Kavanaugh, 2000), such that glutamate was removed from the simulation during transport and reverse transport did not occur. The transporter Markov model comprised four states, connected by the following rates (forward, backward; units are $\mathrm{sec}^{-1} \mathrm{or} \mathrm{M}^{-1} \mathrm{sec}^{-1}$ ): $T_{\text {out }}<>G T_{\text {out }}$ $\left(2 \times 10^{7} \cdot\right.$ [Glu], 300); $G T_{\text {out }}<>G T_{\text {in }}(500,0) ; G T_{\text {in }}<>T_{\text {in }}(2000,0)$; and $T_{\text {in }}<>T_{\text {out }}(40,0)$. In an effort to detect transporter-mediated currents in pyramidal cells, Bergles and Jahr (1998) recorded synaptic responses with $\mathrm{SCN}^{-}$as the major internal anion to maximize the conductance through the transporter-associated anion conductance (Wadiche et al., 1995). Those experiments were simulated here by convolving the time course over which transport events occurred during the simulation with an exponential waveform (peak, $0.427 \mathrm{fA}$; $\tau$ of $3 \mathrm{msec}$, i.e., $8 q_{\mathrm{e}} /$ cycle) to reflect the deactivation of transporter currents in patches (Bergles and Jahr, 1998) and the enhanced current with $\mathrm{SCN}^{-}$(Watzke et al., 2001). To simulate currents with an impermanent anion, the exponential waveform was scaled down to reflect only the net inward flux resulting from the electrogenic transport cycle ( $2 q_{\mathrm{e}}$ /cycle) (Zerangue and Kavanaugh, 1996).

To simulate direct release (see Fig. 9B), 5000 transmitter molecules were released from a point source at the presynaptic membrane into a $500 \times 500 \times 20 \mathrm{~nm}$ synaptic cleft. The diffusion coefficient $(D)$ was set to $1 \times 10^{-6} \mathrm{~cm}^{2} / \mathrm{sec}$. The middle $225 \times 225 \mathrm{~nm}\left(0.05 \mu \mathrm{m}^{2}\right)$ square of the apposed $0.25 \mu \mathrm{m}^{2}$ postsynaptic membrane was occupied by NMDARs (500 $\mu \mathrm{m}^{-2}$, i.e., $\sim 25$ receptors). The cleft glutamate concentration was measured in the cleft space directly above this $0.05 \mu \mathrm{m}^{2}$ square. When included, transporters occupied the remainder of the postsynaptic membrane $\left(5000 \mu \mathrm{m}^{-2}, \sim 1000\right.$ transporters). To simulate indirect release (see Fig. 9A), glutamate was released from a distant point to create a spatially homogeneous transmitter concentration; clearance at the periphery of the simulation was adjusted such that the cleft glutamate concentration peaked at $\sim 1 \mu \mathrm{M}$ and decayed with an exponential time course of $100 \mathrm{msec}$ (see Fig. $9 A$ ). To simulate extrasynaptic activation of NMDARs and transporters (see Fig. 9C), the synapse was replaced with a cube $\left(200 \mathrm{~nm}\right.$ on a side) on which NMDARs $\left(500 \mu \mathrm{m}^{-2}\right)$ and transporters $\left(5000 \mu \mathrm{m}^{-2}\right)$ were evenly distributed; extrasynaptic glutamate concentration was calculated by counting the number of glutamate molecules in the $10 \mathrm{~nm}$ layer of space surrounding the cube. Glutamate release was the same as in the indirect release simulation (see Fig. 9A). Control simulations confirmed that the number of NMDARs $(0-500$ $\mu \mathrm{m}^{-2}$ ) did not affect significantly the glutamate concentration at the membrane (data not shown). The whole-cell extrasynaptic transporter current (see Fig. 9C, right panel) was derived by scaling the simulated transport current measured across the $0.24 \mu \mathrm{m}^{2}$ surface of the cube to reflect transport over $2100 \mu \mathrm{m}^{2}$, equivalent to $10 \%$ of the total membrane surface area within CA1 stratum radiatum of a single pyramidal cell (Bannister and Larkman, 1995a,b).

\section{RESULTS}

If NMDARs at some inactive synapses were activated by glutamate spillover, one would predict that these receptors would encounter a lower [Glu] during a synaptic event than those located in an active synapse. Directly activated receptors could then be distinguished from spillover-activated receptors by examining the actions of a low-affinity, competitive antagonist of the NMDAR. Some weak antagonists, such as D-AA, dissociate so rapidly that they unbind, while synaptically released transmitter remains in the cleft, allowing glutamate to replace the antagonist at some fraction of receptors (Clements et al., 1992). The extent to which this replacement occurs (and therefore the extent of antagonist block) depends on the amplitude and time course of [Glu]. This general approach has been used to estimate the [Glu] time course in the synaptic cleft under different experimental conditions (Clements et al., 1992; Tong and Jahr, 1994; Diamond and Jahr, 1997; Choi et al., 2000).

One limitation of this method is that the antagonist effect, as measured by the decrease in EPSC amplitude, does not indicate a unique transmitter concentration time course. For example, a kinetic model of the NMDAR (Clements et al., 1992; Lester and Jahr, 1992) (Fig. 1A) predicts that $70 \mu \mathrm{M}$ D-AA would block a relatively large, fast transient $\left([\mathrm{Glu}]_{\text {peak }}, 1 \mathrm{~mm} ; \tau_{\text {decay, }} 1 \mathrm{msec}\right)$ (Fig. $1 B)$ and a smaller, slower transient $(2 \mu \mathrm{M}, 300 \mathrm{msec})$ (Fig. $1 C)$ equally well. Systematically varying both the peak [Glu] and the time constant of decay indicates that a particular degree of block by $70 \mu \mathrm{M}$ D-AA could reflect any in a range of [Glu] transients (Fig. 1D). D-AA generally does not change the time course of simulated NMDAR responses, except for a slight slowing of responses to very slow [Glu] transients (Fig. 1C).

The model predicts that, if receptors in some synapses encounter much less glutamate than receptors in other synapses, D-AA could actually speed the NMDAR EPSC decay. For example, NMDARs encountering a relatively large, fast transient (Clements et al., 1992) (Fig. 1B) would be blocked to a lesser extent by D-AA than receptors activated by a smaller, slower transient (1 $\mu \mathrm{M}, 100 \mathrm{msec}$ ) (Fig. 1E). The model also predicts that small transients, if permitted to decay gradually, would activate receptors quite slowly and could give rise to a significantly slowed conductance (Fig. 1E). Therefore, D-AA, by blocking slower components of the EPSC to a greater extent than faster components, could speed the decay of an EPSC comprising directly and indirectly activated synapses (Fig. $1 G$ ). Note that, when fast and slow components are combined at a single synapse, D-AA does not affect the simulated EPSC decay (Fig. $1 F$ ). The two components must occur at separate synapses for D-AA to speed the EPSC decay (Fig. 1G). The effects of D-AA on the simulated EPSC decay are abolished by eliminating spillover altogether or by enlarging and/or prolonging the slow component so that the degree of block is similar in the indirect and direct cases (Fig. 1, compare $B, C)$.

To test whether NMDARs at different synapses encounter a range of [Glu] during a synaptic response, NMDAR EPSCs were recorded from CA1 pyramidal neurons in acute slices of rat hippocampus. Responses were elicited by stimulating Schaffer collateral fibers in stratum radiatum in the presence of DNQX (10 $\mu \mathrm{M})$ and picrotoxin $(100 \mu \mathrm{M})$, to block AMPARs and GABA $\mathrm{A}_{\mathrm{A}}$, respectively. EPSCs exhibited a J-shaped current-voltage relationship that depended on the presence of external $\mathrm{Mg}^{2+}$ and were blocked by the NMDAR antagonist D-CPP $(5 \mu \mathrm{M}$; data not shown). At room temperature $\left(22-24^{\circ} \mathrm{C}\right)$, when pyramidal cells were voltage clamped at $+50 \mathrm{mV}$ to relieve the voltage-dependent $\mathrm{Mg}^{2+}$ block of the channel, the NMDAR EPSC decayed in a multiexponential manner, with a half-decay time $\left(t_{1 / 2}\right)$ of $185 \pm$ $34 \operatorname{msec}($ mean $\pm \mathrm{SD} ; n=28)$ (Fig. $2 A)$.

\section{D-AA speeds the decay of the NMDAR EPSC}

D-AA $(70 \mu \mathrm{M})$ reversibly reduced the NMDAR EPSC amplitude to $32 \pm 11 \%$ of control $(n=8)$ (Fig. $2 A, B)$ and also decreased $t_{1 / 2}$ to $56 \pm 12 \%$ of control $\left(n=8 ; p=6 \times 10^{-5}\right)$. To control for possible changes in space clamp attributable to the decrease in EPSC amplitude, parallel experiments were performed with D-CPP, a high-affinity antagonist that dissociates slowly $\left(k_{\text {off }} \sim 1\right.$ $\mathrm{sec}^{-1}$ ) (Benveniste and Mayer, 1991) such that its efficacy is independent of the glutamate concentration during a synaptic event. Applied at a concentration of $1 \mu \mathrm{M}$, D-CPP blocked the NMDAR EPSC to a similar extent $(37 \pm 12 \% ; n=8)$ as $70 \mu \mathrm{M}$ D-AA $(p=0.1 ; n=8)$. Each drug was applied and then washed out (Fig. $2 B$ ), and the order of application was shuffled such that each drug was applied first in half of the experiments. Although 

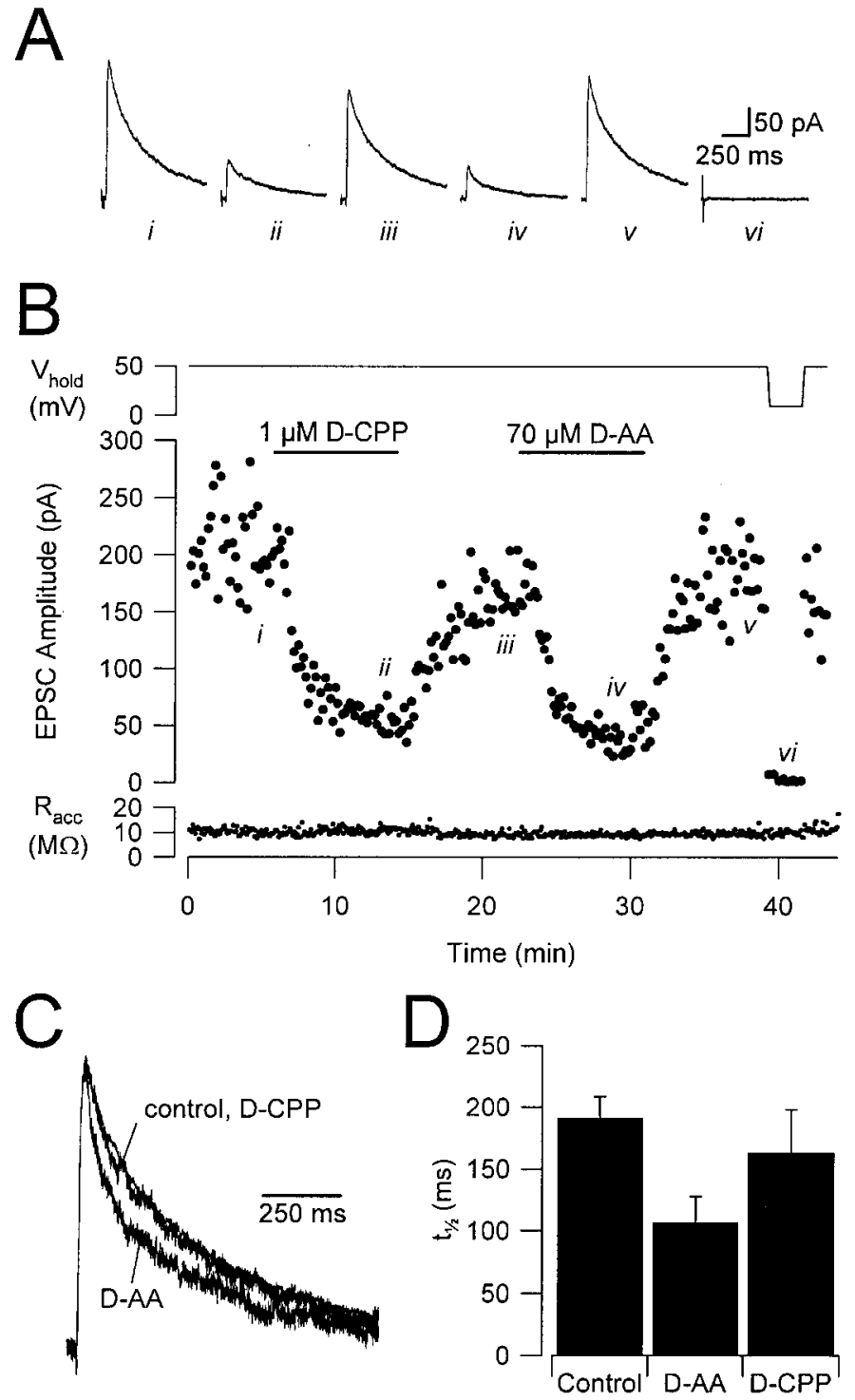

Figure 2. D-AA speeds the decay of the NMDAR EPSC. $A$, NMDAR EPSCs $\left(V_{\mathrm{h}}\right.$ of $\left.+50 \mathrm{mV}\right)$ recorded under control conditions $(i, i i i, v)$ and in the presence of $1 \mu \mathrm{M}$ D-CPP (ii) or $70 \mu \mathrm{M}$ D-AA (iv). Traces represent averages of 20 consecutive responses. Response $v i$ recorded at $V_{\mathrm{h}}$ of +10 mV. $B$, NMDAR EPSC amplitudes over the course of the experiment in $A$. $C$, EPSCs $i i$, iii, and $i v$ from $A$, scaled to the same amplitude. $D$, Half-decay times of NMDAR EPSCs recorded in control solution, in the presence of $70 \mu \mathrm{M} \mathrm{D}-\mathrm{AA}$, or in the presence of $1 \mu \mathrm{M}$ D-CPP. $n=8$.

D-CPP did decrease $t_{1 / 2}$ slightly (to $85 \pm 14 \%$ of control; $n=8$; $p=0.016$ ) (Fig. 2D), the effect of D-CPP on $t_{1 / 2}$ was only one-third that of D-AA ( $p=0.0014 ; n=8)$. The speeding of the NMDAR EPSC by D-AA, interpreted in the context of the kinetic model (Fig. 1), suggests that a wide range of peak [Glu] occurs across the synapses contributing to an NMDAR EPSC.

\section{D-AA does not affect release, glutamate transport, or} NMDAR kinetics

Possible actions of D-AA aside from NMDAR antagonism could complicate the interpretation of the data in Figure 2. To test for presynaptic actions of D-AA, its effects on AMPAR EPSCs were examined in the absence of AMPAR and NMDAR antagonists at $V_{\mathrm{h}}$ of $-60 \mathrm{mV}$, a potential at which NMDARs are blocked by external $\mathrm{Mg}^{2+}$. D-AA did not change the amplitude $(102 \pm 3 \%$ of control; $n=3$ ) or paired-pulse facilitation (94 $\pm 6 \%$ of control; $n=3$ ) of AMPAR EPSCs (Fig. $3 A$ ), indicating that the drug exerts no detectable presynaptic effects. Moreover, D-AA did not affect STCs (Otis et al., 1997) recorded in CA1 astrocytes (amplitude, $101 \pm 5 \%$ of control; $n=3$ ) (Fig. $3 B$ ), responses that are acutely sensitive to changes in release probability (Bergles and Jahr, 1997). In addition to arguing against any presynaptic effects of D-AA, this result demonstrates that the drug does not interfere with glial glutamate transport.

D-AA might also shorten the decay of the NMDAR EPSC by speeding deactivation of the receptor, although previous work has shown this not to be the case (Clements et al., 1992). These results were confirmed by eliciting NMDAR-mediated currents with glutamate in outside-out patches excised from pyramidal cells (Fig. 3C). D-AA caused no significant change in the decay of the response to a brief application of $1 \mathrm{~mm}$ L-glutamate $(114 \pm$ $16 \%$ of control; $n=3$ ) in patches voltage clamped at $+50 \mathrm{mV}$. Similar results were observed at $-60 \mathrm{mV}(94 \pm 6 \%$ of control; $n=3$; data not shown).

\section{Distinguishing between spillover and "whispering" synapses}

The speeding of the NMDAR EPSC decay by D-AA suggests that the NMDARs activated during an EPSC are exposed to a range of transmitter concentration profiles. Some receptors appear to encounter high glutamate concentrations and, as a result, are blocked relatively weakly by D-AA (Fig. $1 B$ ). Other receptors encounter lower glutamate concentrations, and, as a result, their activation is slower and more strongly blocked by D-AA. One interpretation is that NMDARs at some synapses encounter a lower concentration of glutamate because the transmitter spills over from another, distant synapse. However, it is also possible that different synapses (or even individual events at the same synapse) could present widely different glutamate concentrations to synaptic receptors as a result of variations in vesicular transmitter content or the rate at which transmitter escapes the vesicle during exocytosis (Choi et al., 2000; Fisher et al., 2001). One way to distinguish between spillover and low-glutamate, so-called "whispering" synapses would be to examine the extent to which glutamate transport limits NMDAR activation. High-affinity, sodium-dependent glutamate transporters restrict extrasynaptic glutamate diffusion (Asztely et al., 1997; Bergles and Jahr, 1998). Transport has a much smaller effect on [Glu] within an active synapse (Diamond and Jahr, 1997), perhaps because most transporters are located extrasynaptically in glial membranes (Lehre and Danbolt, 1998) and a steep concentration gradient drives the rapid clearance of glutamate from the cleft. Therefore, although transport ought to limit activation of NMDARs by glutamate spillover (Asztely et al., 1997), it would be unlikely to affect significantly the [Glu] time course at a whispering synapse.

Glutamate transport was diminished with TBOA (Shimamoto et al., 1998), a competitive transporter antagonist that does not interact with NMDARs (Jabaudon et al., 1999). To gauge the degree of transporter blockade by TBOA (and the consequent slowing of glutamate clearance), STCs were recorded from astrocytes in CA1 stratum radiatum. TBOA reduced the amplitude of the STC (and prolonged its decay) in a dose-dependent manner (Fig. 4). TBOA at $30 \mu \mathrm{M}$ caused a fourfold decrease in the STC amplitude (to $27 \pm 4 \%$ of control; $n=4$ ) and a fourfold increase in the exponential decay time constant $(440 \pm 60 \%$ of control; $n=4)$. TBOA at $30 \mu \mathrm{M}$ exerted a greater blockade of the STC than $300 \mu \mathrm{M}$ dihydrokainic acid (Bergles and Jahr, 1997; Diamond 

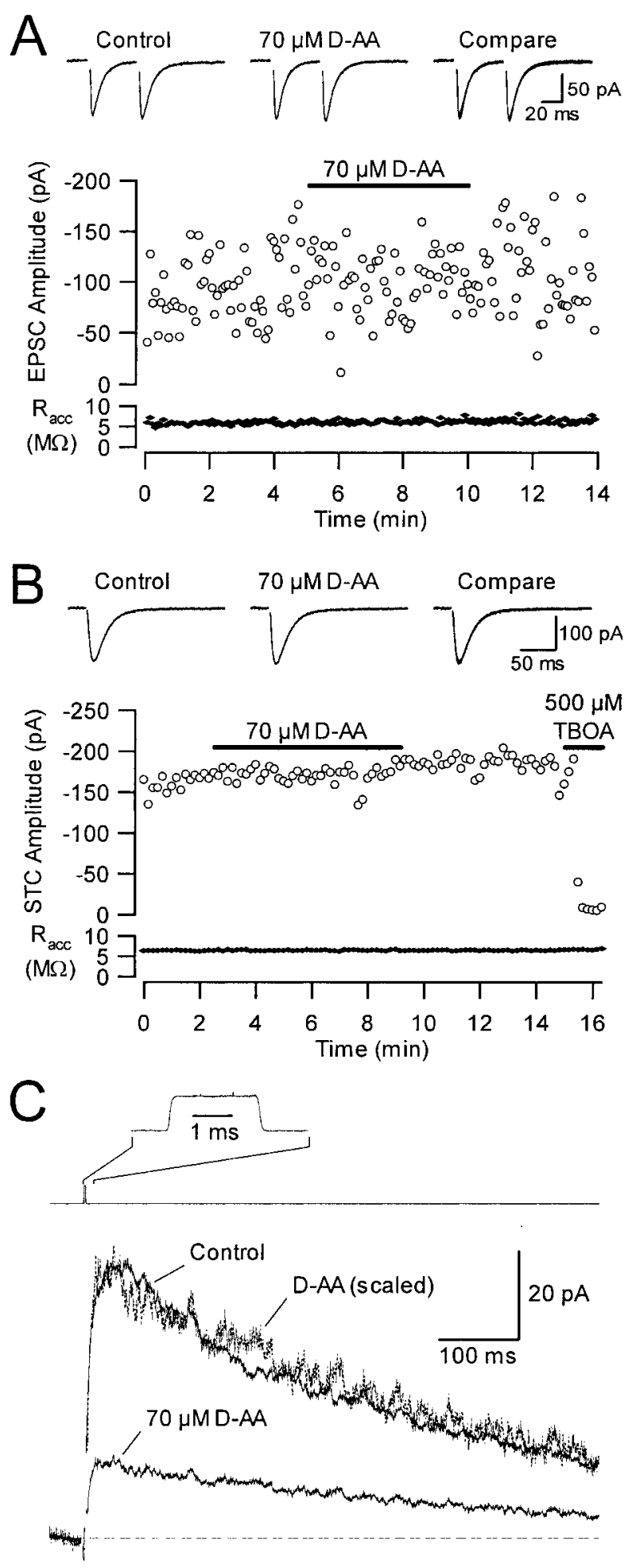

Figure 3. D-AA does not affect release probability, glutamate transport, or NMDAR kinetics. $A$, AMPAR EPSCs $\left(V_{\mathrm{h}}\right.$ of $-70 \mathrm{mV}$; no AMPAR or NMDAR antagonists present). Control trace (top panel) reflects average of 25 EPSCs before application of D-AA. Traces in control and D-AA are overlaid in the right panel for comparison. $B$, STCs recorded from astrocytes $\left(V_{\mathrm{h}}\right.$ of $-95 \mathrm{mV}$; AMPAR and NMDAR antagonists present). Responses in control solution (left panel) and in D-AA (middle panel) are overlaid for comparison (right panel). $C$, NMDAR currents elicited in an outside-out excised patch by a brief application of $1 \mathrm{~mm}$ L-glutamate. Top panel shows "open-tip" current, obtained at the end of the experiment after patch rupture to check the speed of solution exchange across the patch pipette. $V_{\mathrm{h}}$ of $+60 \mathrm{mV}$.
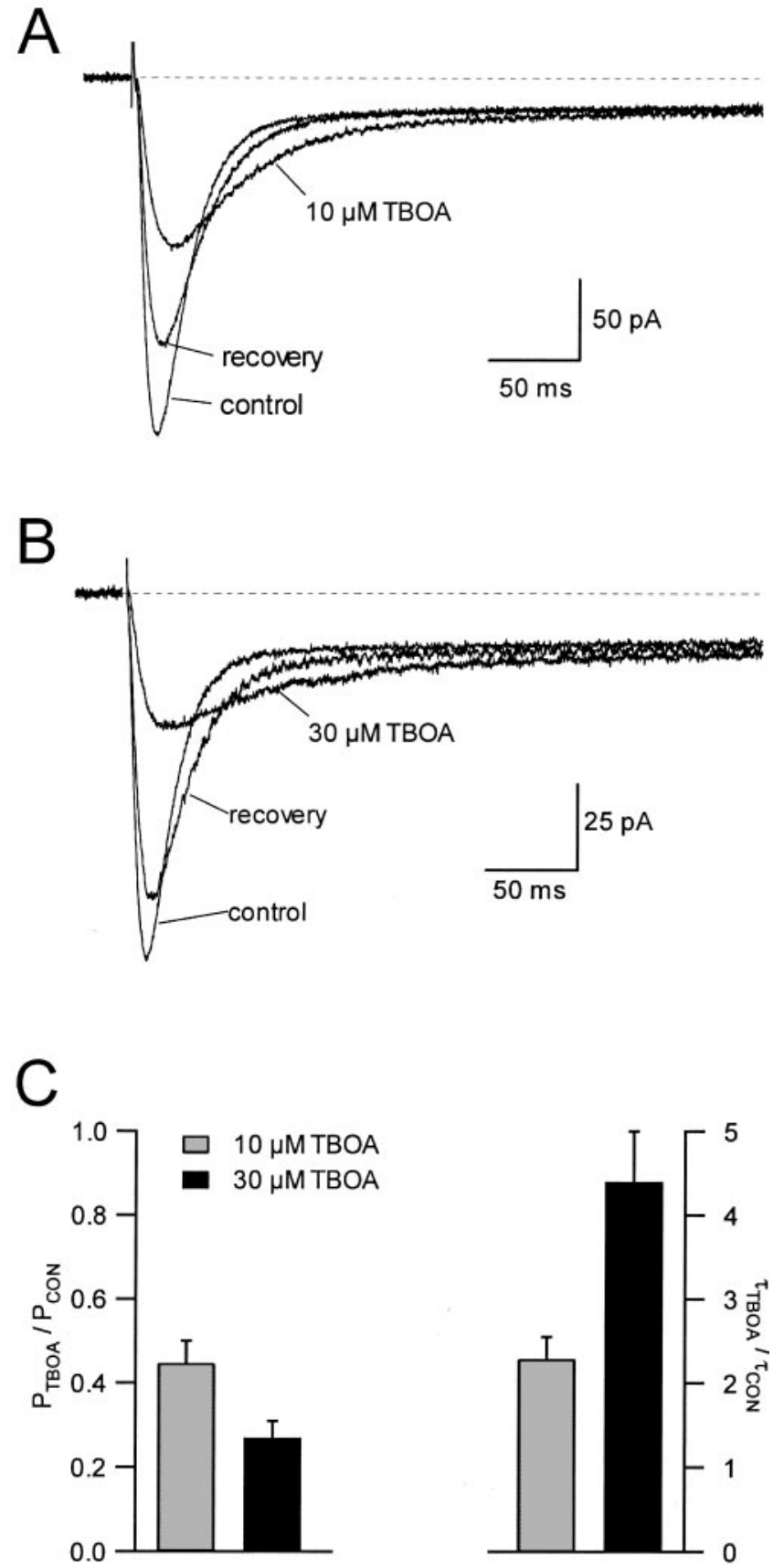

Figure 4. Effects of TBOA on astrocyte STCs. $A$, TBOA at $10 \mu \mathrm{M}$ reversibly reduced the amplitude and slowed the decay of the STC. $B$, Effects of $30 \mu \mathrm{M}$ TBOA on the STC (different astrocyte than in $A$ ). $C$, Effects of $10 \mu \mathrm{M}(n=4)$ and $30 \mu \mathrm{M}(n=4)$ TBOA on STC amplitude $\left(P_{\mathrm{TBOA}} / P_{\mathrm{CON}}\right)$ and exponential decay $\left(\tau_{\mathrm{TBOA}} / \tau_{\mathrm{CON}}\right)$. Amplitudes were calculated by subtracting the peak from the amplitude of the slowlydecaying potassium current (Bergles and Jahr, 1997) measured 400-450 msec after stimulation.

and Jahr, 2000), which completely blocks GLT-1 (Arriza et al., 1994), the transporter subtype that constitutes $80 \%$ of the glial transporter population (Lehre and Danbolt, 1998). Nonetheless, the remaining transporters cleared synaptically released glutamate within a few hundred milliseconds of its release (exponential $\tau$ of $78 \pm 10 \mathrm{msec} ; n=4$ ). The notion that a small fraction of the available transporters could effectively remove synaptically released glutamate from the extracellular space was supported by 

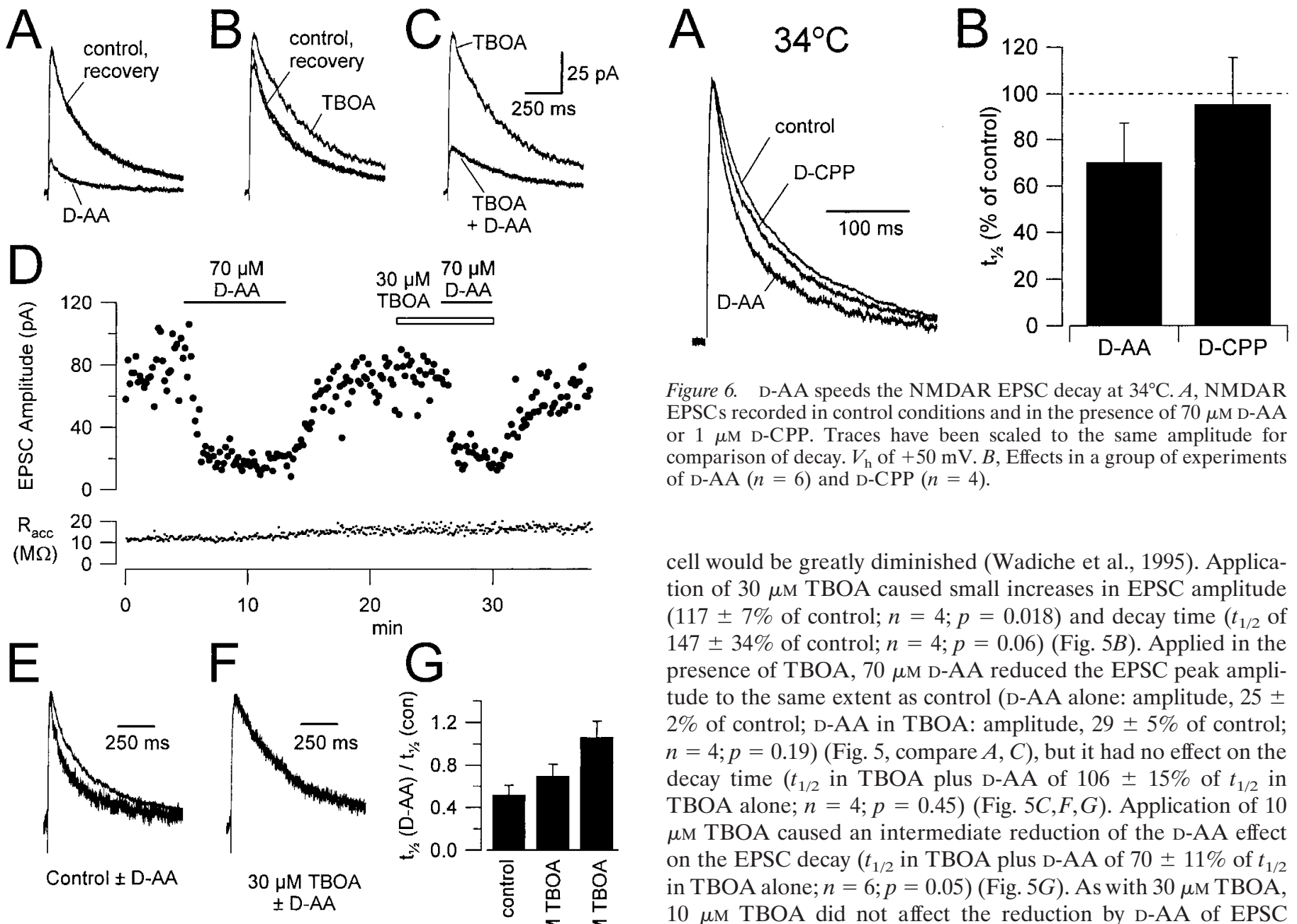

Figure 6. D-AA speeds the NMDAR EPSC decay at $34^{\circ} \mathrm{C}$. $A$, NMDAR EPSCs recorded in control conditions and in the presence of $70 \mu \mathrm{M}$ D-AA or $1 \mu \mathrm{M}$ D-CPP. Traces have been scaled to the same amplitude for comparison of decay. $V_{\mathrm{h}}$ of $+50 \mathrm{mV} . B$, Effects in a group of experiments of D-AA $(n=6)$ and D-CPP $(n=4)$.

cell would be greatly diminished (Wadiche et al., 1995). Application of $30 \mu \mathrm{M}$ TBOA caused small increases in EPSC amplitude $(117 \pm 7 \%$ of control; $n=4 ; p=0.018)$ and decay time $\left(t_{1 / 2}\right.$ of $147 \pm 34 \%$ of control; $n=4 ; p=0.06$ ) (Fig. $5 B$ ). Applied in the presence of TBOA, $70 \mu \mathrm{M}$ D-AA reduced the EPSC peak amplitude to the same extent as control (D-AA alone: amplitude, $25 \pm$ $2 \%$ of control; D-AA in TBOA: amplitude, $29 \pm 5 \%$ of control; $n=4 ; p=0.19$ ) (Fig. 5, compare $A, C$ ), but it had no effect on the decay time $\left(t_{1 / 2}\right.$ in TBOA plus D-AA of $106 \pm 15 \%$ of $t_{1 / 2}$ in TBOA alone; $n=4 ; p=0.45$ ) (Fig. 5C,F,G). Application of 10 $\mu \mathrm{M}$ TBOA caused an intermediate reduction of the D-AA effect on the EPSC decay ( $t_{1 / 2}$ in TBOA plus D-AA of $70 \pm 11 \%$ of $t_{1 / 2}$ in TBOA alone; $n=6 ; p=0.05$ ) (Fig. $5 G$ ). As with $30 \mu \mathrm{M}$ TBOA, $10 \mu \mathrm{M}$ TBOA did not affect the reduction by D-AA of EPSC amplitude $(n=6 ; p=0.36)$. These results indicate that blocking transporters preferentially enhanced activation of the receptors, contributing to slower, more D-AA-sensitive components of the EPSC, suggesting that these receptors were activated by glutamate spillover. Of course, neighboring synapses are located at a range of distances from an active synapse; as a result, reducing transport is likely to affect each indirectly activated synapse differently. However, $30 \mu \mathrm{M}$ TBOA appeared to enhance [Glu] at synapses mediating the slow components of the EPSC such that, on average, the [Glu] at those synapses competed with D-AA, as well as the [Glu] mediating the fast components.

\section{D-AA speeds NMDAR EPSC at near-physiological temperature}

The kinetics of NMDA receptors and glutamate transporters are strongly temperature dependent (e.g., $Q_{10}$ of transport, 3) (Wadiche and Kavanaugh, 1998; Auger and Attwell, 2000), although diff usion is not $\left(Q_{10}\right.$ of 1.3) (Hille, 1984). To test whether receptor activation by spillover is present at more physiological temperatures (Asztely et al., 1997), the experiments described in Figure 2 were repeated at $34^{\circ} \mathrm{C}$ (Fig. $6 A$ ). At $34^{\circ} \mathrm{C}$, the NMDAR EPSC decayed more rapidly $\left(t_{1 / 2}\right.$ of $\left.62 \pm 13 \mathrm{msec} ; n=6\right)$ than at room temperature ( $p<10^{-9}$; unpaired $t$ test). Nonetheless, D-AA (70 $\mu \mathrm{M})$ sped the decay of the EPSC significantly $\left(t_{1 / 2}\right.$ of $70 \pm 17 \%$ of control; $n=6 ; p=0.009)$, whereas D-CPP did not $\left(t_{1 / 2}\right.$ of $95 \pm$ $20 \%$ of control; $n=4 ; p=0.66$ ) (Fig. $6 B$ ), suggesting that NMDARs are activated by spillover even at near-physiological temperatures.

\section{TBOA reduces effects of D-AA on late component of NMDAR EPSCs}

Next, the effects of D-AA on NMDAR EPSCs in pyramidal cells were compared in control conditions and in the presence of TBOA (Fig. 5). Neurons were voltage clamped at $+50 \mathrm{mV}$, a potential at which any glutamate transport into the postsynaptic 


\section{Spillover does not require transmitter pooling between active synapses}

Is glutamate released at a single synapse sufficient to activate receptors in neighboring synapses, or does activation of receptors by spillover require pooling of glutamate released from several active synapses? At cerebellar parallel fiber-Purkinje cell synapses, the extent of spillover depends on the spatiotemporal density of synaptic activity, because it is enhanced by highfrequency and high-intensity stimulation (Carter and Regehr, 2000). If this were true in CA1, increasing stimulus strength should enhance spillover and decrease the effect of D-AA on the NMDAR EPSC decay, similar to the effect of blocking transporters with TBOA (Fig. 5). This was tested by varying the stimulus intensity over a threefold range, which in control solution caused proportional changes in EPSC amplitude and insignificant changes in half-decay time ( $p=0.30 ; n=6$; one-way ANOVA) (Fig. $7 B$ ). Although the effects of D-AA on EPSC decay were not significantly different at different stimulus intensities $(p=0.89$; repeated-measures ANOVA; $n=6$ ) (Fig. $7 D$ ), the trend in the data indicated a small reduction in the effects of D-AA on $t_{1 / 2}$ with stronger stimulation, suggesting that activation of more synapses may slightly exacerbate spillover. These effects of increasing stimulus intensity were, however, quite subtle compared with those induced by blocking transporters (compare Figs. $5 G, 7 D$ ), consistent with glial cell recordings that showed the decay of the STC to be slowed by competitive transporter antagonists but unaffected by stimulus intensity (Diamond and Jahr, 2000). These results do not demonstrate directly that glutamate released from a single synapse is sufficient to activate NMDARs in neighboring synapses, but the fact that D-AA sped the decay of even the smallest NMDAR EPSCs (Fig. 7D) supports the possibility that spillover does not require activation of multiple synapses.

\section{Postsynaptic transporters limit NMDAR activation by glutamate spillover}

All of the NMDAR EPSCs described thus far were recorded at $+50 \mathrm{mV}$, a potential at which glutamate transport into the postsynaptic neuron is greatly diminished (Brew and Attwell, 1987; Barbour et al., 1991; Wadiche et al., 1995). The physiological role of neuronal transporters in the hippocampus is poorly understood. Hippocampal pyramidal cells express glutamate transporters (Rothstein et al., 1994; He et al., 2000), but the large majority of synaptically released glutamate in the hippocampus is taken up by glial transporters (Rothstein et al., 1996; Bergles and Jahr, 1998; Lehre and Danbolt, 1998; Kojima et al., 1999; Diamond and Jahr, 2000) and STCs are not detected in pyramidal cells (Bergles and Jahr, 1998). To test whether neuronal transporters limit glutamate spillover, extracellular $\mathrm{Mg}^{2+}$ was replaced with $\mathrm{Ca}^{2+}$, allowing NMDAR EPSCs to be recorded at both positive and negative potentials (Fig. 8A). NMDAR EPSCs decayed significantly faster at negative potentials than at positive potentials $(t / 2$, neg, $46 \pm 15 \%$ of $t 1 / 2$,pos; $n=6 ; p=0.0018)$. D-AA reduced the EPSC amplitude at both potentials, but it sped the EPSC decay only at positive potentials (positive potentials: $t_{1 / 2}$, $57 \pm 20 \%$ of control; $n=6 ; p=0.0049$; negative potentials: $t_{1 / 2}$, $100 \pm 10 \%$ of control; $n=6 ; p=0.80$ ) (Fig. $8 B, E$ ). D-CPP exerted little effect on the EPSC decay at positive or negative potentials $(n=4)$ (Fig. 8C). Thus, no NMDAR activation by spillover was detected at negative potentials. It appears unlikely that this result reflects any voltage dependence of NMDAR affinity for either D-AA or glutamate. Competitive antagonists bind and unbind the NMDAR in a voltage-independent manner
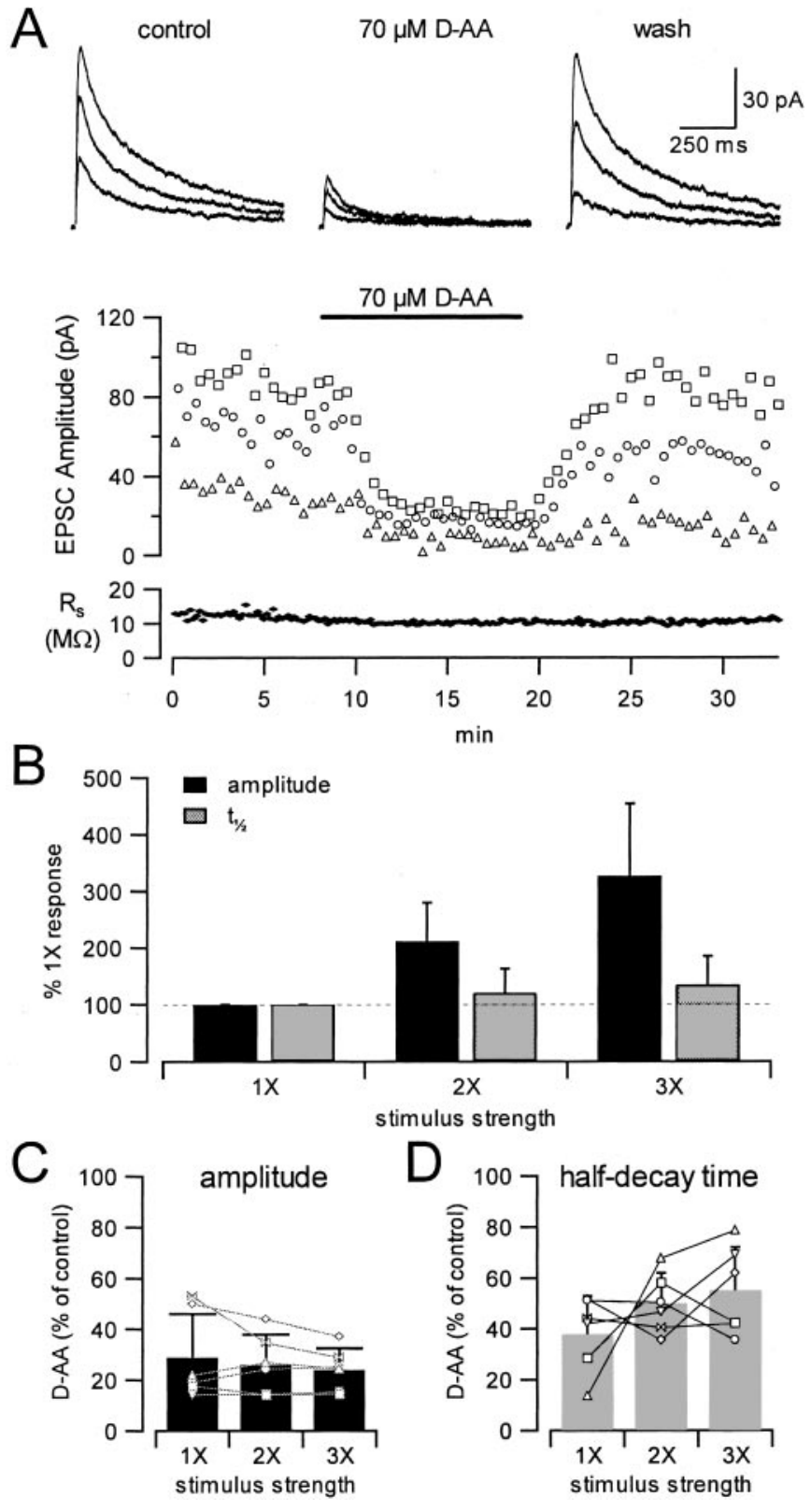

Figure 7. Effects of D-AA on NMDAR EPSCs elicited by a range of stimulus intensities. $A$, NMDAR EPSCs $\left(V_{\mathrm{h}}\right.$ of $\left.+50 \mathrm{mV}\right)$ were elicited by 75 (triangles), 150 (circles), and 225 (squares) $\mu \mathrm{A}$ stimulation. Stimuli were interleaved throughout experiment. $B$, Effects of changing stimulus intensity on EPSC amplitude (black bars) and half-decay time (gray bars). Data pooled from six experiments. $C$, Effects of D-AA on EPSC amplitude at different stimulus intensities. $D$, Effects of D-AA on EPSC half-decay time at different stimulus intensities. Data in $C$ and $D$ were taken from same six cells as $B$. Data from individual cells are superimposed on bar graphs in $C$ and $D$.

(Benveniste and Mayer, 1991), and the dose-response relationship of NMDARs to glutamate in excised patches was not different at negative and positive potentials $(n=4$ patches; $p=0.2$; data not shown).

If the voltage dependence of NMDAR activation by spillover reflects a role for postsynaptic glutamate transporters, then blocking transport in the recorded cell should rescue the effect of D-AA at negative potentials. Glutamate transporters bind intracellular potassium and transport it out of the cell to complete the trans- 


\section{A}


Figure 8. D-AA speeds NMDAR EPSC decay only when postsynaptic transport is inhibited. $A$, NMDAR EPSCs were recorded at -60 or +60 $\mathrm{mV}$ (as indicated in top panel), and the effects of D-AA and D-CPP were compared at both potentials. $B$, EPSCs from the experiment shown in $A$, recorded in control conditions and in the presence of $70 \mu \mathrm{M}$ D-AA. Responses in antagonist have been duplicated and scaled (dashed lines) to control response for comparison of decay time course. Inset, Comparison of control EPSCs recorded at negative $(i)$ and positive (ii) potentials. $C$, as in $B$, except recordings are in control and in the presence of $1 \mu \mathrm{M}$ D-CPP. $D$, Effects of $70 \mu \mathrm{M}$ D-AA and $1 \mu \mathrm{M}$ D-CPP at $V_{\mathrm{h}}$ of $-70 \mathrm{mV}$ with NMDG in the patch pipette. No synaptic current was observed when $V_{\mathrm{h}}$ was $+60 \mathrm{mV}$. Responses at $-70 \mathrm{mV}$ were scaled to the control response for comparison of decay time course. Control EPSC amplitude was 240 pA. $E$, Effects of D-AA on NMDAR EPSC half-decay time at negative and positive potentials with $\mathrm{Cs}^{+}$in the recording pipette and at negative potentials with NMDG in the pipette. Experiments were performed at $22^{\circ} \mathrm{C}$ (black bars) or $34^{\circ} \mathrm{C}$ (gray bars). Numbers in each bar indicate number of cells tested. port cycle (Kanner and Bendahan, 1982; Barbour et al., 1991). Cesium can replace potassium in the cycle (Barbour et al., 1991; Auger and Attwell, 2000), but larger cations such as choline cannot (Barbour et al., 1991). To block the complete cycling of neuronal transporters in pyramidal cells, cesium was replaced in the intracellular patch solution with NMDG. NMDAR EPSCs recorded at positive potentials were abolished within 5-7 min after break-in with NMDG in the pipette (Fig. 8D), suggesting that NMDG diffused rapidly to postsynaptic sites and failed to permeate NMDAR channels. At negative potentials, the NMDAR EPSC decayed more slowly with NMDG in the pipette $\left(t_{1 / 2}\right.$ of $\left.147 \pm 8 \mathrm{msec} ; n=5\right)$ than with cesium $\left(t_{1 / 2}\right.$ of $95 \pm 20$ msec; $n=6 ; p<0.001$; unpaired $t$ test). Although within-cell comparisons were not made, NMDG did not appear to affect EPSC amplitude at negative potentials. With NMDG in the pipette, $70 \mu \mathrm{M}$ D-AA sped the decay of the NMDAR EPSC at negative potentials $\left(t_{1 / 2}\right.$ of $55 \pm 11 \%$ of control; $n=5 ; p=$ 0.0011) (Fig. $8 D, E$ ), whereas in the same cells, $1 \mu \mathrm{M} \mathrm{D}-\mathrm{CPP}$ had no significant effect $\left(t_{1 / 2}\right.$ of $93 \pm 18 \%$ of control; $\left.n=5 ; p=0.48\right)$ (Fig. 8D). Analogous results were observed at $34^{\circ} \mathrm{C}$; D-AA sped the decay of the NMDAR EPSC at negative potentials with NMDG as the internal cation $(80 \pm 11 \%$ of control; $n=5 ; p=$ 0.03 ) but not with Cs (96 $\pm 8 \%$ of control; $n=5 ; p=0.30$ ) (Fig. $8 E)$. Together, these results indicate that postsynaptic, neuronal transporters limit glutamate diff usion into quiescent synapses and that the postsynaptic membrane potential may influence the degree to which NMDARs are activated by glutamate spillover.

\section{DISCUSSION}

The results presented here argue that glutamate diffusion between excitatory synapses is sufficient to activate NMDARs in quiescent synapses in the CA1 region of the hippocampus. Glutamate spillover was observed after single stimuli and did not increase substantially at higher stimulus intensities, consistent with previous reports in CA1 showing that spillover is unaffected by changes in release probability (Asztely et al., 1997). Although a role for transmitter pooling between synapses cannot be excluded, evidence for spillover even in relatively small synaptic responses (Fig. 7) suggests that it may occur after glutamate release from a single synapse. In contrast, spillover between parallel fiber-stellate cell synapses in the cerebellum requires high-frequency stimulation (HFS) and is enhanced by stronger stimulation (Carter and Regehr, 2000).

For glutamate spillover to be detected with D-AA (as in Fig. 2), indirectly activated synapses must give rise to a significantly slowed NMDAR conductance. It is possible, therefore, that this method detects only low levels of spillover at distant synapses and is insensitive to larger, more transient [Glu] waveforms at nearestneighbor synapses that produce NMDAR conductances similar in time course to those at directly activated synapses (Rusakov and Kullmann, 1998). If NMDARs activated by spillover contributed to the EPSC peak, however, one would predict that reducing glutamate uptake with TBOA would increase the EPSC amplitude and diminish the effect of D-AA on the peak. Both 10 and 30 $\mu \mathrm{M}$ TBOA made the EPSC slightly larger, but neither concentration changed the effect of D-AA on the amplitude (Fig. 5) (see Results). Although this result is inconsistent with a significant contribution of spillover to the peak of the EPSC, it is also likely that spillover to those synapses closest to the release site is the least sensitive to transporter blockade. 
A indirect
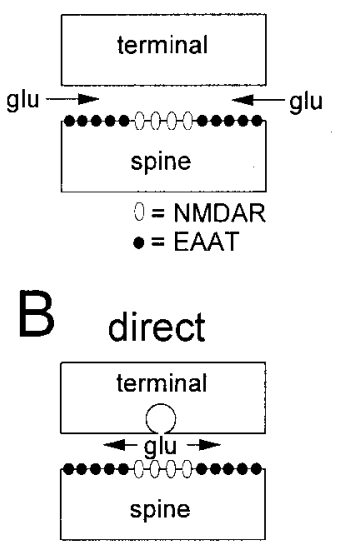

C extrasynaptic

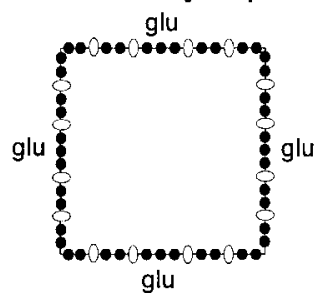

glu [glutamate]
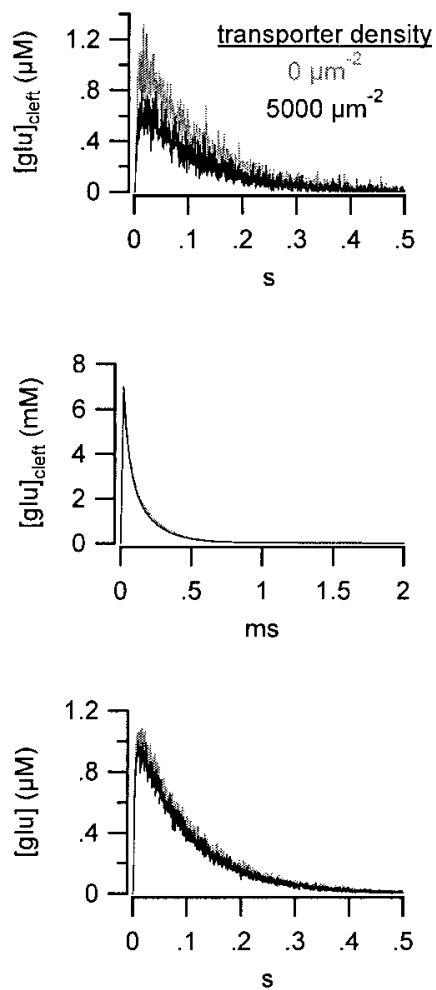

NMDAR activation
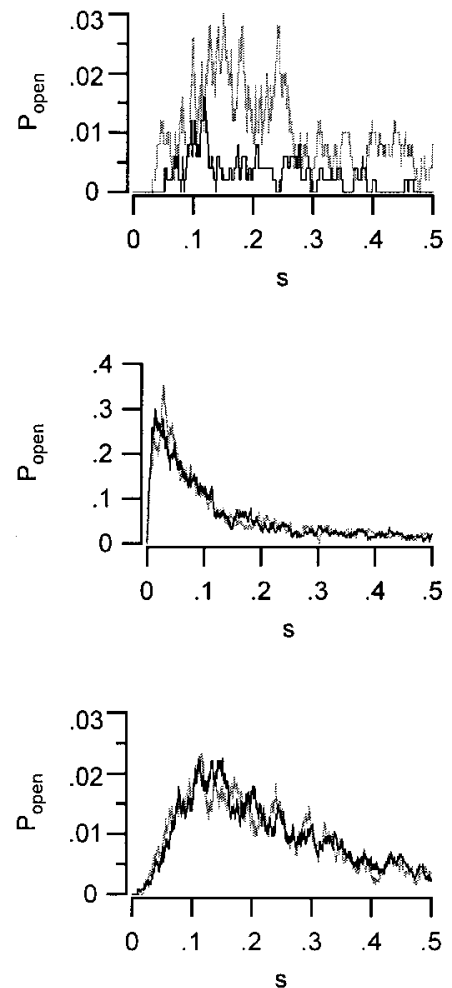

neuronal transport
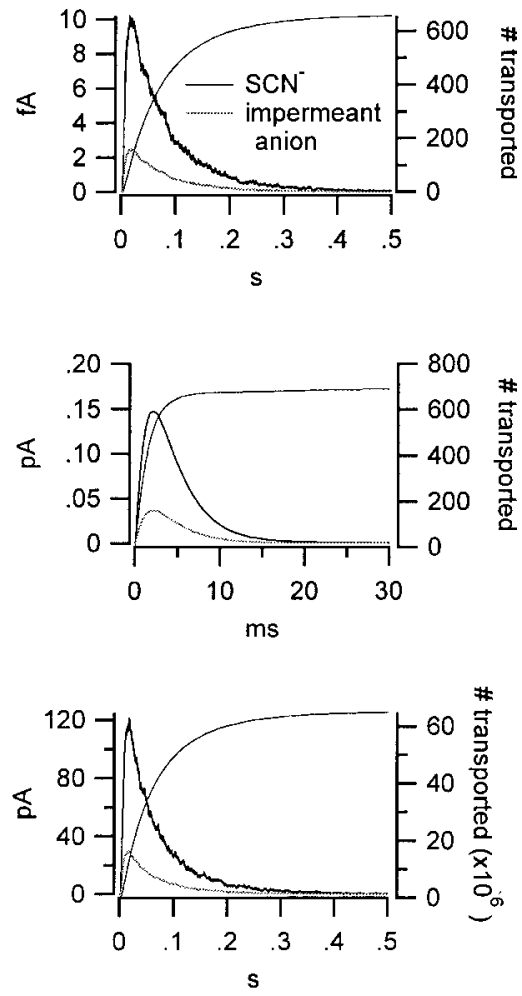

Figure 9. Monte Carlo simulation of indirect, direct, and extrasynaptic NMDAR activation. A diffusion model (see Materials and Methods) was designed to simulate the effects of neuronal transporters in different scenarios. $A$, Indirect activation. Glutamate diff used into the synaptic cleft from a distant release site. NMDARs (white ovals) were located in the center of the postsynaptic density, and glutamate transporters (black circles) were located perisynaptically. The number of glutamate molecules released and rate of clearance from simulation were adjusted to yield a homogeneous concentration that peaked at $1 \mu \mathrm{M}$ and decayed with an exponential time constant of $100 \mathrm{msec}$. Dense, perisynaptic transporter expression $\left(5000 \mu \mathrm{m}^{-2}, \sim 1000\right.$ transporters total) reduced the amount of glutamate that reached the NMDARs (second panel) and, consequently, reduced NMDAR activation (third panel). This reduction in $[\mathrm{Glu}]_{\text {cleft }}$ required the uptake of $>600$ glutamate molecules ( fourth panel). Traces reflect averages of 20 simulations. $B$, Direct activation. Panels are the same as in $A$, except that a quantum of glutamate (5000 molecules) was released from within the synaptic cleft. Perisynaptic transporters did not affect the glutamate concentration in the cleft or in NMDAR activation. Traces reflect the average of 10 simulations. $C$, Extrasynaptic activation, as in $A$ and $B$, except that NMDARs $\left(500 \mu \mathrm{m}^{-2}\right)$ and transporters $\left(5000 \mu \mathrm{m}^{-2}\right)$ were distributed randomly in the extrasynaptic membrane. Glutamate was released from a distance, as in $A$. Whole-cell transporter currents (right panel) were scaled to reflect transport into the pyramidal cell during an evoked response if synaptically released glutamate were to reach $10 \%$ of the pyramidal cell membrane in stratum radiatum (see Materials and Methods). Traces reflect the average of 10 simulations.

\section{A physiological role for neuronal transporters}

One common characteristic of glutamate spillover in CA1 and in other regions is that it is enhanced by blocking glutamate uptake (Otis et al., 1996; Asztely et al., 1997; Lozovaya et al., 1999; Overstreet et al., 1999; Carter and Regehr, 2000). Neuronal transporters in Purkinje cells take up a significant fraction of synaptically released glutamate (Otis et al., 1997; Auger and Attwell, 2000). In CA1, a role for neuronal transporters is unclear, because the large majority of uptake is accomplished by glia (Rothstein et al., 1996; Bergles and Jahr, 1998; Lehre and Danbolt, 1998; Kojima et al., 1999; Diamond and Jahr, 2000). Accordingly, reducing glial transport significantly enhanced glutamate spillover (Figs. 4,5). The data presented in Figure 8 demonstrate, however, that neuronal transporters also limit the extent to which NMDARs in inactive synapses are activated by glutamate spillover. Spillover was observed only at positive potentials, when transport is diminished, or when transporters in the postsynaptic cell were disrupted by NMDG applied through the patch pipette (Fig. $8 D, E$ ). Because membrane potential does not change the affinity of the transporter for glutamate (Mennerick et al., 1999), the effect observed here may reflect actual transport into the postsynaptic cell.

At first, the role for neuronal transporters described here seems at odds with evidence that pyramidal cells do not exhibit measurable transporter currents either in response to synaptic stimulation or in excised patches (Bergles and Jahr, 1998). However, a simple diffusion model of an excitatory synapse (Fig. 9) (see Materials and Methods) suggests that strategic subcellular localization may allow a relatively small number of transporters to play an important role. If, for example, transporters were expressed perisynaptically on CA1 pyramidal cells, as indicated by ultrastructural studies (He et al., 2000), they could restrict NMDAR activation by low levels of glutamate diffusing into the synapse from outside (Fig. 9A). The $1 \mu \mathrm{M}, 100 \mathrm{msec}$ transient used here and Figure 1 was chosen merely as an example, although diff usion simulations do predict that [Glu] decays very slowly once it falls well below the affinity of glial glutamate uptake $\left(k_{\mathrm{d}} \sim 13 \mu \mathrm{M}\right)$ (Bergles and Jahr, 1997; Rusakov and Kullmann, 1998). The actual [Glu] waveform is likely to vary widely across indirectly activated synapses. Perisynaptic transporters have relatively little 
impact on receptor activation when glutamate is released from within the synapse, because diffusion plays the dominant role in clearing glutamate rapidly from the cleft (Clements et al., 1992) (Fig. 9B). In either case, the resulting neuronal transporter current would be small, even under conditions maximizing the contribution of the transporter-associated anion conductance, i.e., with a highly permeable internal anion such as $\mathrm{SCN}^{-}$(Bergles and Jahr, 1998; Wadiche and Kavanaugh, 1998; Watzke et al., 2001). Thus, neuronal transport could play an important role in limiting glutamate spillover while remaining difficult to detect with standard electrophysiological methods.

\section{Alternative explanations for the effects of D-AA}

The effects of D-AA described above demonstrate that, during an EPSC, NMDARs encounter a wide range of [Glu] waveforms. For the time course of the NMDAR conductance to be slower than that already imposed by the slow kinetics of the channel (Lester et al., 1990), the [Glu] waveform must peak at a much lower level and decay much more slowly than thought to occur in an active synapse after exocytosis (Clements et al., 1992) (Fig. 1). Peak [Glu] could vary significantly within a single synapse, but large differences in decay time would be unlikely to occur within even the largest synaptic contacts made between Schaffer collateral fibers and CA1 pyramidal cells $\left(\sim 0.11 \mu \mathrm{m}^{2}\right)$ (Schikorski and Stevens, 1997). It is probable that the [Glu] waveform in an active synapse comprises fast and slow components, but such a combination does not predict an effect of D-AA on the decay of the simulated EPSC (Fig. $1 F$ ). This result is not an artifact of nearly complete NMDAR occupancy by the simulated fast component (Clements et al., 1992) (Fig. 1B), because similar results are observed (data not shown) when the fast component achieves only 50\% NMDAR occupancy (Mainen et al., 1999).

NMDARs appear to be expressed primarily in postsynaptic densities (Fritschy et al., 1998). Nonetheless, it is possible that the effects observed here reflect activation of extrasynaptic NMDARs rather than receptors located in neighboring synaptic contacts. Although it is difficult to rule it out directly, this possibility seems unlikely. Differences in NMDAR activation were observed by blocking the transporters in a single pyramidal cell (Fig. 8), suggesting that transporters on one neuron can reduce the glutamate concentration encountered by NMDARs on the same cell. The diff usion model suggests, however, that even a very large number of extrasynaptic transporters would limit extrasynaptic NMDAR activation only slightly, and that this uptake would result in a sizeable transporter current (Fig. 9C). This conflicts with synaptic recordings in pyramidal cells, which show no detectable transporter-mediated component (Bergles and Jahr, 1998). Moreover, blockade of GLT-1, the primary glial glutamate transporter, does not decrease significantly the amount of synaptically released glutamate transported by hippocampal astrocytes (Diamond and Jahr, 2000), suggesting that the remaining glial transporters (the GLAST subtype) are competent to take up transmitter and that no other significant glutamate sink competes with glial transporters. If neuronal transporters were expressed primarily perisynaptically (He et al., 2000), even at very high density (e.g., $5000 \mu \mathrm{m}^{-2}$ ) (Fig. 9), they would likely be well outnumbered by GLAST on the surrounding glial membranes (Lehre and Danbolt, 1998).

\section{Implications for synaptic transmission}

Glutamate spillover has been posed as an alternative explanation (Asztely et al., 1997) for the experimental observation of NMDA- only, "silent" synapses (Isaac et al., 1995; Liao et al., 1995). Indeed, the dependence of the spillover observed here on the postsynaptic membrane potential might explain, in part, why the quantal content of NMDAR EPSCs is greater at positive potentials (Niu et al., 1998). However, silent synapses are evident at negative holding potentials (Liao et al., 1995) in conditions under which spillover was not detected with the method used here, although spillover onto closely neighboring synapses may elicit an NMDAR conductance that is not significantly slower than at an active synapse, making it more difficult to detect with D-AA.

The results presented here suggest that, when the postsynaptic cell membrane remains relatively hyperpolarized during conditions of low or moderate activity, neuronal transporters help limit NMDAR activation by spillover. However, HFS, like that required to induce long-term potentiation (LTP) (Bliss and Collingridge, 1993), could depolarize the postsynaptic membrane sufficiently to decrease neuronal transport (transport at $-20 \mathrm{mV}$ is only $\sim 30 \%$ as efficient as at $-70 \mathrm{mV}$ ) (Wadiche et al., 1995) and encourage NMDAR activation by spillover. If a number of synapses were activated even weakly by spillover during HFS, collectively they could increase postsynaptic depolarization and, consequently, calcium influx through NMDARs at both directly and indirectly activated synapses. However, the low levels of NMDAR activation at any one of the "indirect" synapses may not admit sufficient calcium to induce LTP (Malenka, 1991); moderately activated synapses may even undergo long-term depression (Cummings et al., 1996). Thus, glutamate spillover could enhance the induction of LTP while preserving, and possibly improving, its synapse specificity.

\section{REFERENCES}

Arriza JL, Fairman WA, Wadiche JI, Murdoch GH, Kavanaugh MP, Amara SG (1994) Functional comparisons of three glutamate transporter subtypes cloned from human motor cortex. J Neurosci 14:5559-5569.

Asztely F, Erdemli G, Kullmann DM (1997) Extrasynaptic glutamate spillover in the hippocampus: dependence on temperature and the role of active glutamate uptake. Neuron 18:281-293.

Auger C, Attwell D (2000) Fast removal of synaptic glutamate by postsynaptic transporters. Neuron 28:547-558.

Bannister NJ, Larkman AU (1995a) Dendritic morphology of CA1 pyramidal neurones from the rat hippocampus. I. Branching patterns. J Comp Neurol 360:150-160.

Bannister NJ, Larkman AU (1995b) Dendritic morphology of CA1 pyramidal neurones from the rat hippocampus. II. Spine distributions J Comp Neurol 360:161-171.

Barbour B, Brew H, Attwell D (1991) Electrogenic uptake of glutamate and aspartate into glial cells isolated from the salamander (Ambystoma) retina. J Physiol (Lond) 436:169-193.

Benveniste M, Mayer ML (1991) Structure-activity analysis of binding kinetics for NMDA receptor competitive antagonists: the influence of conformational restriction. Br J Pharmacol 104:207-221.

Bergles DE, Jahr CE (1997) Synaptic activation of glutamate transporters in hippocampal astrocytes. Neuron 19:1297-1308.

Bergles DE, Jahr CE (1998) Glial contribution to glutamate uptake at Schaffer collateral-commissural synapses in the hippocampus. J Neurosci 18:7709-7716.

Bergles DE, Dzubay JA, Jahr CE (1997) Glutamate transporter currents in bergmann glial cells follow the time course of extrasynaptic glutamate. Proc Natl Acad Sci USA 94:14821-14825.

Bliss TV, Collingridge GL (1993) A synaptic model of memory: longterm potentiation in the hippocampus. Nature 361:31-39.

Brew H, Attwell D (1987) Electrogenic glutamate uptake is a major current carrier in the membrane of axolotl retinal glial cells. Nature [Erratum (1987) 328:742] 327:707-709.

Carter AG, Regehr WG (2000) Prolonged synaptic currents and glutamate spillover at the parallel fiber to stellate cell synapse. J Neurosci 20:4423-4434.

Choi S, Klingauf J, Tsien RW (2000) Postfusional regulation of cleft glutamate concentration during LTP at "silent synapses." Nat Neurosci 3:330-336.

Clark BA, Barbour B (1997) Currents evoked in Bergmann glial cells by 
parallel fibre stimulation in rat cerebellar slices. J Physiol (Lond) 502:335-350

Clements JD, Lester RA, Tong G, Jahr CE, Westbrook GL (1992) The time course of glutamate in the synaptic cleft. Science 258:1498-1501.

Cummings JA, Mulkey RM, Nicoll RA, Malenka RC (1996) $\mathrm{Ca}^{2+}$ signaling requirements for long-term depression in the hippocampus. Neuron 16:825-833.

Diamond JS, Jahr CE (1997) Transporters buffer synaptically released glutamate on a submillisecond time scale. J Neurosci 17:4672-4687.

Diamond JS, Jahr CE (2000) Synaptically released glutamate does not overwhelm transporters on hippocampal astrocytes during highfrequency stimulation. J Neurophysiol 83:2835-2843.

Fisher RJ, Pevsner J, Burgoyne RD (2001) Control of fusion pore dynamics during exocytosis by munc18. Science 291:875-878.

Fritschy JM, Weinmann O, Wenzel A, Benke D (1998) Synapse-specific localization of NMDA and GABA(A) receptor subunits revealed by antigen-retrieval immunohistochemistry. J Comp Neurol 390:194-210.

He Y, Janssen WG, Rothstein JD, Morrison JH (2000) Differential synaptic localization of the glutamate transporter EAAC1 and glutamate receptor subunit GluR2 in the rat hippocampus. J Comp Neurol 418:255-269.

Hille B (1984) Ionic channels of excitable membranes, Ed 1. Sunderland, MA: Sinauer.

Isaac JT, Nicoll RA, Malenka RC (1995) Evidence for silent synapses: implications for the expression of LTP, p 195. Neuron 15:427-434.

Jabaudon D, Shimamoto K, Yasuda-Kamatani Y, Scanziani M, Gahwiler BH, Gerber U (1999) Inhibition of uptake unmasks rapid extracellular turnover of glutamate of nonvesicular origin. Proc Natl Acad Sci USA 96:8733-8738.

Kanner BI, Bendahan A (1982) Binding order of substrates to the sodium and potassium ion coupled L-glutamic acid transporter from rat brain. Biochemistry 21:6327-6330.

Kojima S, Nakamura T, Nidaira T, Nakamura K, Ooashi N, Ito E, Watase K, Tanaka K, Wada K, Kudo Y, Miyakawa H (1999) Optical detection of synaptically induced glutamate transport in hippocampal slices. J Neurosci 19:2580-2588.

Kullmann DM, Erdemli G, Asztely F (1996) LTP of AMPA and NMDA receptor-mediated signals: evidence for presynaptic expression and extrasynaptic glutamate spill-over. Neuron 17:461-474.

Lehre KP, Danbolt NC (1998) The number of glutamate transporter subtype molecules at glutamatergic synapses: chemical and stereological quantification in young adult rat brain. J Neurosci 18:8751-8757.

Lester RA, Jahr CE (1992) NMDA channel behavior depends on agonist affinity. J Neurosci 12:635-643.

Lester RA, Clements JD, Westbrook GL, Jahr CE (1990) Channel kinetics determine the time course of NMDA receptor-mediated synaptic currents. Nature 346:565-567.

Liao D, Hessler NA, Malinow R (1995) Activation of postsynaptically silent synapses during pairing-induced LTP in CA1 region of hippocampal slice. Nature 375:400-404.

Lozovaya NA, Kopanitsa MV, Boychuk YA, Krishtal OA (1999) Enhancement of glutamate release uncovers spillover-mediated transmission by $N$-methyl-D-aspartate receptors in the rat hippocampus. Neuroscience 91:1321-1330.

Mainen ZF, Malinow R, Svoboda K (1999) Synaptic calcium transients in single spines indicate that NMDA receptors are not saturated. Nature 399:151-155.

Malenka RC (1991) Postsynaptic factors control the duration of synaptic enhancement in area CA1 of the hippocampus. Neuron 6:53-60.

Mennerick S, Shen W, Xu W, Benz A, Tanaka K, Shimamoto K, Isenberg KE, Krause JE, Zorumski CF (1999) Substrate turnover by transporters curtails synaptic glutamate transients. J Neurosci 19:9242-9251.

Min MY, Rusakov DA, Kullmann DM (1998) Activation of AMPA, kainate, and metabotropic receptors at hippocampal mossy fiber synapses: role of glutamate diffusion. Neuron 21:561-570.

Mitchell SJ, Silver RA (2000) Glutamate spillover suppresses inhibition by activating presynaptic mGluRs. Nature 404:498-502.

Niu YP, Xiao MY, Wigstrom H (1998) Variability of AMPA and NMDA receptor mediated responses in CA1 pyramidal cells of young rats. Brain Res 800:253-259.

Otis TS, Kavanaugh MP (2000) Isolation of current components and partial reaction cycles in the glial glutamate transporter EAAT2. J Neurosci 20:2749-2757.
Otis TS, Wu YC, Trussell LO (1996) Delayed clearance of transmitter and the role of glutamate transporters at synapses with multiple release sites. J Neurosci 16:1634-1644.

Otis TS, Kavanaugh MP, Jahr CE (1997) Postsynaptic glutamate transport at the climbing fiber-Purkinje cell synapse. Science 277:1515-1518.

Overstreet LS, Kinney GA, Liu YB, Billups D, Slater NT (1999) Glutamate transporters contribute to the time course of synaptic transmission in cerebellar granule cells. J Neurosci 19:9663-9673.

Rossi DJ, Alford S, Mugnaini E, Slater NT (1995) Properties of transmission at a giant glutamatergic synapse in cerebellum: the mossy fiber-unipolar brush cell synapse. J Neurophysiol 74:24-42.

Rothstein JD, Martin L, Levey AI, Dykes-Hoberg M, Jin L, Wu D, Nash N, Kuncl RW (1994) Localization of neuronal and glial glutamate transporters. Neuron 13:713-725.

Rothstein JD, Dykes-Hoberg M, Pardo CA, Bristol LA, Jin L, Kuncl RW, Kanai Y, Hediger MA, Wang Y, Schielke JP, Welty DF (1996) Knockout of glutamate transporters reveals a major role for astroglial transport in excitotoxicity and clearance of glutamate. Neuron 16:675-686.

Rusakov DA, Kullmann DM (1998) Extrasynaptic glutamate diffusion in the hippocampus: ultrastructural constraints, uptake, and receptor activation. J Neurosci 18:3158-3170.

Sakmann B, Stuart G (1995) Patch-pipette recordings from the soma, dendrites, and axon of neurons in brain slices. In: Single-channe recording, Ed 2 (Sakmann B, Neher E, eds), pp 199-211. New York: Plenum

Scanziani M, Salin PA, Vogt KE, Malenka RC, Nicoll RA (1997) Usedependent increases in glutamate concentration activate presynaptic metabotropic glutamate receptors. Nature 385:630-634.

Schikorski T, Stevens CF (1997) Quantitative ultrastructural analysis of hippocampal excitatory synapses. J Neurosci 17:5858-5867.

Schrader LA, Tasker JG (1997) Presynaptic modulation by metabotropic glutamate receptors of excitatory and inhibitory synaptic inputs to hypothalamic magnocellular neurons. J Neurophysiol 77:527-536.

Semyanov A, Kullmann DM (2000) Modulation of GABAergic signaling among interneurons by metabotropic glutamate receptors. Neuron 25:663-672.

Shimamoto K, Lebrun B, Yasuda-Kamatani Y, Sakaitani M, Shigeri Y, Yumoto N, Nakajima T (1998) DL-threo-beta-benzyloxyaspartate, a potent blocker of excitatory amino acid transporters. Mol Pharmacol 53:195-201.

Silver RA, Colquhoun D, Cull-Candy SG, Edmonds B (1996) Deactivation and desensitization of non-NMDA receptors in patches and the time course of EPSCs in rat cerebellar granule cells. J Physiol (Lond) 493:167-173.

Stiles JR, Van Helden D, Bartol Jr TM, Salpeter EE, Salpeter MM (1996) Miniature endplate current rise times less than 100 microseconds from improved dual recordings can be modeled with passive acetylcholine diffusion from a synaptic vesicle. Proc Natl Acad Sci USA 93:5747-5752.

Tanaka K, Watase K, Manabe T, Yamada K, Watanabe M, Takahashi K, Iwama H, Nishikawa T, Ichihara N, Kikuchi T, Okuyama S, Kawashima N, Hori S, Takimoto M, Wada K (1997) Epilepsy and exacerbation of brain injury in mice lacking the glutamate transporter GLT-1. Science 276:1699-1702.

Tong G, Jahr CE (1994) Block of glutamate transporters potentiates postsynaptic excitation. Neuron 13:1195-1203.

Trussell LO, Zhang S, Raman IM (1993) Desensitization of AMPA receptors upon multiquantal neurotransmitter release. Neuron 10:1185-1196.

Vogt KE, Nicoll RA (1999) Glutamate and gamma-aminobutyric acid mediate a heterosynaptic depression at mossy fiber synapses in the hippocampus. Proc Natl Acad Sci USA 96:1118-1122.

Wadiche JI, Kavanaugh MP (1998) Macroscopic and microscopic properties of a cloned glutamate transporter/chloride channel. J Neurosci 18:7650-7661.

Wadiche JI, Amara SG, Kavanaugh MP (1995) Ion fluxes associated with excitatory amino acid transport. Neuron 15:721-728.

Watzke N, Bamberg E, Grewer C (2001) Early intermediates in the transport cycle of the neuronal excitatory amino acid carrier eaac1. J Gen Physiol 117:547-562.

Zerangue N, Kavanaugh MP (1996) Flux coupling in a neuronal glutamate transporter. Nature 383:634-637. 